\title{
A crise social desenhada pelas crianças: imaginação e conhecimento social
}

\section{The social crisis drawn by children: imagination and social knowledge}

\author{
Manuel Jacinto Sarmento* \\ Gabriela Trevisan**
}

\begin{abstract}
RESUMO
A crise social e económica que tem atingido o mundo desde 2008, com efeitos especialmente sentidos nos países do Sul da Europa, causou impactos fortes e visíveis na infância, como o aumento das taxas efetivas e de risco de pobreza e a vulnerabilidade e a exposição a fatores de risco social e de perda consistente de direitos. A análise dessas incidências tem vindo a ser trabalhada num conjunto de relatórios nacionais e internacionais, de ONG's e estudos académicos. No entanto, poucos estudos têm dedicado atenção ao modo como a interpretação das representações das crianças sobre a crise é feita e sobre as expressões específicas que estas assumem na sua vida quotidiana. As crianças são capazes de observar os modos como a crise impacta o seu próprio grupo geracional, bem como os adultos que mais lhe são próximos. Da mesma forma, promovem interpretações económicas sobre os fenómenos, sejam elas mais "ingénuas" ou mais complexas. Este artigo incide sobre as representações das crianças sobre a crise social e económica em Portugal. São especialmente analisadas narrativas gráficas produzidas por crianças oriundas de classes trabalhadoras, com idades compreendidas entre os 6 e os 10 anos de idade. Por meio dessas narrativas, as crianças constroem formas visuais a partir da sua imaginação sobre a sua condição. Assim, a imaginação das crianças é um modo de acesso ao conhecimento na sociedade onde se inserem e aos seus modos próprios de compreensão de realidades complexas.
\end{abstract}

Palavras-chave: Pobreza infantil. Narrativas gráficas. Crise económica. Infância.

DOI: $10.1590 / 0104-4060.51387$

* Universidade do Minho. Instituto de Educação. Braga, Portugal. Campus de Gualtar. 4710-057. E-mail: sarmento@ie.uminho.pt

** Escola Superior de Educação Paula Frassinetti e CIEC/Universidade do Minho. Porto, Portugal. Rua Gil Vicente 138-142. 4000-255. E-mail: gabriela.trevisan@esepf.pt 


\begin{abstract}
The social and economic crisis that has hit the world since 2008, with effects strongly felt in the countries of Southern Europe, has had fierce and visible impacts in childhood with the increase of the effective rates, the risk of poverty and vulnerability, and the exposure to factors of social risk and consistent loss of rights. The analysis of these incidents has been worked on in a series of national and international reports from NGOs and academic studies. However, few studies have devoted attention to the way in which the interpretation of the representations of children about the crisis is made and the specific expressions that they assume in their daily lives. Children are able to observe the ways in which the crisis affects their own generational group as well as the adults closest to them. In the same way, they promote economic interpretations of phenomena, whether "naïve" or more complex. This article focuses on the representations of children about the social and economic crisis in Portugal. Graphical narratives produced by children from working classes, aged between 6 and 10 years old, are given focus. From these narratives, children construct visual forms from their imagination about their social condition. Thus, the child's imagination is a way of accessing knowledge in the society they belong to and their own way of understanding complex realities.
\end{abstract}

Keywords: Child poverty. Graphic narratives. Economic crisis. Childhood.

\title{
Introdução
}

A aplicação de planos de austeridade aos países do Sul da Europa, decorrente da gestão imposta pela coligação entre o Fundo Monetário Internacional (FMI), o Banco Central Europeu e a Comissão Europeia, na sequência da crise económica e financeira iniciada em 2008 e dos seus reflexos no agravamento das dívidas soberanas desses países, teve impactos diretos e indiretos no quotidiano das crianças e no seu bem-estar. Em 2013, 2.5 milhões de crianças encontravam-se em risco de pobreza e exclusão social na Europa (Eurochild \& EAPN, 2013).

O conceito de pobreza infantil é ambíguo e presta-se a diferentes modos de quantificação, conforme a entidade ou agência que a realiza (Eurostad, Unicef, sistemas estatísticos nacionais etc.), por isso a necessidade de ele ser clarificado. A mobilização de noções qualitativas afigura-se como indispensável, a par dos indicadores quantitativos sobre o rendimento disponível nas famílias e nas crianças, face às suas necessidades alimentares, habitacionais, educacionais, sanitárias etc. Num relatório publicado precisamente sobre a pobreza infantil em 
consequência da crise, as redes europeias Eurochild e European Anti-Poverty Network (EAPN) apresentavam a sua noção de pobreza infantil:

As crianças vivem em pobreza se o rendimento e os recursos disponíveis para o seu sustento são inadequados para terem um padrão de vida considerado aceitável na sociedade em que vivem e tido como suficiente para assegurar o seu desenvolvimento social, emocional e físico. Devido ao aumento da pobreza, as crianças e as suas famílias podem experimentar múltiplas carências devido aos baixos rendimentos, ambiente e habitação pobres, cuidados de saúde insuficientes e dificuldades na educação. Elas são frequentemente excluídas e marginalizadas de atividades sociais, desportivas, recreativas e culturais que normalmente outras crianças usufruem e em que participam. $\mathrm{O}$ acesso daquelas crianças aos direitos fundamentais pode ser restringido e limitado, elas podem experimentar situações de estigmatização e discriminação e as suas vozes podem ser não escutadas. (Eurochild \& EAPN, 2013, p. 9).

A colocação da pobreza infantil num quadro mais geral que procura interpretá-la como multidimensional e especialmente articulada com as condições de bem-estar (onde se situa a privação material) constitui hoje um aspeto central da teorização sobre infância e exclusão social. Também a Unicef (2012) coloca a questão da pobreza infantil no âmbito do bem-estar, definindo os seus principais aspetos: bem-estar material, segurança e saúde, bem-estar educacional, na família e nas relações com pares, comportamentos e risco e o bem-estar subjetivo, ou seja, o modo como as crianças se sentem em relação a si próprias. Apesar de as condições materiais não serem o único determinante do bem-estar, desempenham uma grande parte do mesmo, particularmente ao providenciarem as condições de acesso a diferentes recursos, nomeadamente os que ajudam ao exercício de direitos fundamentais e à promoção de inclusão social. Assim, estar em situação de pobreza poderá ter diferentes significados para as crianças, nomeadamente: não ter dinheiro necessário para comer de modo saudável e equilibrado; não ser capaz de comprar roupas novas e calçados; não ter equipamentos que outras crianças têm garantidos, como livros e equipamentos de lazer, tais como uma bicicleta ou um skate; viver em casas pobres ou sobrelotadas; viver com aquecimento pouco adequado; ausência de um local tranquilo com espaço suficiente e luz para realizar os trabalhos da escola; não aceder a cuidados de saúde adequados ou cuidados de qualidade à infância ou frequentar uma boa escola; ter poucas possibilidades de brincar em parques infantis não vandalizados, participar em desportos e em atividades culturais/ 
criativas; ter reduzida participação nas decisões que afetam a vida quotidiana (Eurochild \& EAPN, 2013, p. 11).

Existem, em conclusão, efeitos específicos da crise nas crianças. Vários relatórios e estudos têm vindo a debruçar-se especificamente na análise dos efeitos da crise na infância e no quotidiano das crianças (Harper et al., 2009; Bastos, 2015; De Neubourg et al., 2012; Martorano et al., 2013; Sarasa \& Luppi, 2012; Wall et al., 2014a; Wall et al., 2014b; Sarmento, Fernandes \& Trevisan, 2015). Apesar da crise económica afetar especialmente as crianças e as famílias de mais baixos recursos, e da sua gestão ter aumentado significativamente as desigualdades sociais, todas as crianças foram afetadas (Rodrigues, 2016). Porém, elas foram afetadas de modo diferenciado. As crianças mais pobres são as que sofreram mais elevadas restrições nos seus direitos de proteção e de provisão. Pode mesmo se falar numa regressão desses direitos. Assim, importa extrair a conclusão de que, ao tratar-se dos efeitos da crise na infância, é necessário, ao mesmo tempo, considerar a infância como uma categoria geracional própria e as diferentes posições sociais das crianças e de suas famílias, articulando dialeticamente a identidade da infância com a diversidade das suas condições de vida.

Relativamente à realidade portuguesa, país que - juntamente com a Grécia, a Espanha e a Irlanda - foi especialmente atingido pela gestão austeritária da crise económica e financeira, pode apresentar-se a seguinte síntese:

a) A partir da crise económica e financeira, a situação relativa da pobreza infantil agravou-se em todos os seus indicadores: aumentou a taxa de pobreza infantil, o risco de pobreza e a posição relativa das crianças face a outros grupos geracionais: as crianças são o grupo com mais elevada taxa de pobreza, estando uma em cada quatro crianças portuguesas em situação de pobreza.

b) Ao mesmo tempo, nos anos de gestão austeritária da crise (2010 a 2015), houve uma redução significativa do apoio económico do Estado às famílias. A partir de 2010, o acesso a prestações sociais que depende do rendimento das famílias - e.g. Abono de Família, Ação Social Escolar, Subsídios Sociais de Parentalidade, Rendimento Social de Inserção e Subsídio Social de Desemprego - ficou mais restrito, não só em termos do número de famílias beneficiárias mas também dos montantes atribuídos.

c) A situação é agravada pelos cortes salariais, pelo aumento dos impostos e pelo agravamento das taxas de desemprego.

d) A ausência de políticas de família e de infância agrava o problema, por efeito de não atribuição de prioridade à infância, quando ela é mais urgente do que nunca, e por inadequação dos instrumentos de 
regulação dos efeitos das políticas de austeridade sobre as populações mais vulneráveis.

e) Em resultado disso, a situação da infância em Portugal pode caracterizar-se nestes números alarmantes: as crianças são, desde 2008, o grupo geracional com maior risco de pobreza; uma em cada quatro crianças vive em privação material e uma em cada dez crianças em situação de privação material severa; o risco de pobreza é mais elevado nas famílias numerosas (41\%), nas famílias monoparentais $(31 \%)$ e nas pessoas desempregadas (38\%); as famílias monoparentais com o progenitor desempregado apresentam um risco quase absoluto de pobreza $(90 \%)$; $30 \%$ das crianças perderam o direito ao abono de família em 3 anos (2009 a 2012); as políticas públicas direcionadas às famílias são manifestamente insuficientes, não integradas nem adequadas à gravidade da situação (Wall et al., 2014a).

Estes dados acentuam dois aspetos fundamentais: a crise económica excluiu as crianças mais pobres das condições normativas da infância contemporânea, no que respeita aos direitos de provisão - educação, alimentação e saúde - mas também de proteção - da família, levando a situação global da infância para um estado pior do que o verificado antes da proclamação dos direitos da criança através da Convenção sobre os Direitos da Criança. O retorno às condições normativas da infância está, assim, diretamente ligado à produção de condições políticas que reconheçam e ampliem os direitos sociais das crianças e das suas famílias, bem como atendam às condições contextuais da vida familiar e à participação das crianças na construção dos seus mundos de vida.

\section{Narrativas gráficas e representações das crianças sobre a crise}

Tal como tem sido referido em diferentes investigações e a partir de diferentes contextos de vida das crianças, estas são atores capazes de identificar, interpretar e questionar os modos como as situações de crise as afetam em diferentes domínios da vida pública e privada.

Alguns relatórios sobre a pobreza (Martorano et al., 2013) têm ressalvado a ideia de que as crianças compreendem efeitos micro e macro das crises económicas na vida das famílias; são capazes de formular diferentes explicações e soluções para a crise, replicam e recriam interpretações adultas nos seus próprios termos e entendem que a sua participação é legítima e adequada. É face a esta constatação que a ideia de estudar as crianças e as suas interpretações 
sobre a crise são pertinentes, em particular pela singularidade interpretativa que são capazes de produzir.

A voz das crianças na investigação científica é aqui entendida como revelação das perceções das crianças, das representações sociais e da própria realidade social: as crianças projetam nas suas interpretações imagens e formas concetuais que são importantes para o conhecimento do mundo social. Isto é, as interpretações da realidade social feita pelas crianças constituem parte da reflexividade institucional da modernidade e, nesse sentido, alargam o campo interpretativo disponível.

A voz das crianças carateriza-se, principalmente, pela polivocidade: exprimem-se de múltiplos modos, desde a linguagem verbal à linguagem gestual, passando pelas imagens, desenhos e registos que as crianças fazem. No sentido de capturar essa polivocidade, temos desenvolvido metodologias apropriadas para a sua interpretação (Sarmento, 2011, 2014; Trevisan, 2014), em particular, no âmbito da análise dos desenhos das crianças, onde nos propomos interpretá-los enquanto "narrativas gráficas", isto é, enquanto conteúdos estruturados com uma sequência temporal onde perpassam interpretações construídas pelas crianças.

$\mathrm{Na}$ análise dos desenhos infantis tem ganho espessura e relevância o conceito de "narrativa criativa" ou "narrativa gráfica" (Faulkner \& Coates, 2011). Este conceito é relevante não apenas porque nos diz que os desenhos das crianças contam uma história - não sendo, por isso, como erroneamente por vezes se faz crer, impulsionados por um qualquer impulso de representação realista, mas, pelo contrário, resultam da imaginação transfiguradora do real que a criança põe em prática através das linhas ou das cores que seleciona e inscreve no papel - como, também, porque nos induz à interpretação dos desenhos como uma linguagem, isto é como a atualização criativa e sempre renovada de códigos expressivos e comunicacionais gráficos. As metodologias visuais nos estudos da criança encontram no conceito de narrativa gráfica um importante recurso, na medida em que ele favorece a hermenêutica das formas culturais de constituição das crianças como sujeitos de cultura e atores sociais.

As narrativas gráficas são frequentemente acompanhadas de processos de verbalização. Se é verdade que a cuidadosa audição do que as crianças dizem enquanto estão envolvidas em atividades criativas nos pode permitir o acesso às fontes e influências das suas formas gráficas e aos sentidos que lhes atribuem (Coates \& Coates, 2011), nem sempre é possível realizar essa audição. A linguagem gráfica das crianças não depende da expressão verbal e a interpretação dos desenhos infantis, uma vez balizadas as condições subjetivas e objetivas da sua produção, pode ser feita, com um elevado controlo dos riscos de ambiguidade, na pressuposição de que qualquer ato comunicativo é polissémico e, portanto, suscetível de várias interpretações simultâneas. Em todo o caso, o 
levantamento e estudo do diálogo entre formas expressivas diferenciadas pode contribuir para um estudo mais centrado nas crianças e menos enviesados por olhares adultocêntricos.

As narrativas gráficas constituem-se continuamente entre um apelo realista e uma projeção imaginária, através dos quais as crianças, por efeito da imaginação simbólica, dão conta de factos, emoções, sentimentos, aspirações e desejos. A interpretação das narrativas gráficas deve considerar o contexto social de emergência, os sentidos explícitos, os elementos formais e suas gramáticas (códigos de cores, figuras, traços identitários etc.), mas também o que é apenas sugerido. Há uma inerente ambiguidade, própria da linguagem plástica, que tem elementos evocativos e não se reduzem à transposição mimética de formas da realidade. A procura dos elementos alusivos e sugestivos estabelece-se numa lógica de construção intersubjetiva do conhecimento, através da apresentação de hipóteses verosímeis e coerentes para os elementos plásticos construídos pelas crianças. A impossibilidade de um "discurso da verdade" sobre os desenhos infantis não inibe as possibilidades explicativas, que se devem articular continuamente com outros dados de investigação, numa perspetiva de triangulação.

As afirmações feitas pelas crianças sobre a crise e os desenhos analisados são parte do acervo de dados constituídos no âmbito do projeto Carta da Cidadania Infanto-Juvenil, que se desenvolve num município no norte de Portugal. O projeto tem como principal objetivo criar, no plano municipal, um instrumento de governança capaz de garantir a construção de políticas integradas para a infância e a juventude. No seu desenvolvimento, envolve diretamente, nas diferentes fases e etapas, a participação cidadã de crianças e de jovens. Ele visa dar resposta a um dos principais problemas identificados nas políticas para a Infância e Juventude: a sua fragmentação e compartimentação, a par da ausência de crianças e jovens na participação da construção das políticas públicas. No projeto estão envolvidas centenas de crianças e jovens, reunidos em grupos focais e numa assembleia (conselho de cidadania), especificamente constituída, onde se promoveu o debate temático sobre o estado de concretização dos direitos no contexto municipal e nas perspetivas de desenvolvimento futuro.

As metodologias de recolha das posições das crianças são múltiplas, desde a intervenção direta nos grupos focais à intervenção nos órgãos participativos, à realização de desenhos e de entrevistas individuais. $\mathrm{O}$ foco é a representação da realidade social da vida das crianças no município, em todos os domínios (direitos sociais, condições de vida, educação, território, mobilidade, ambiente, saúde, acesso à cultura e ao lazer, relações sociais e familiares, participação política).

Atualmente, o projeto prossegue em torno da constituição do município enquanto "Cidade Amiga das Crianças", título atribuído pela Unicef. 
Neste texto, analisaremos apenas os desenhos feitos por crianças sob o tema "a crise". O contexto concreto de produção dos desenhos que analisamos de seguida é um Ateliê de Tempos Livres, e todos os que aqui apresentamos foram realizados em julho de 2015, com crianças entre os 6 e os 12 anos de idade.

\section{Os desenhos}

Apresentaremos nove desenhos, todos eles realizados em papel branco e a lápis negro. A austeridade do meio de produção é propositada. Pretende-se com isso permitir que as ilustrações sejam estritamente centradas no essencial. A classificação dos desenhos será feita em torno de quatro eixos: impactos da crise; ricos e pobres; representação política; soluções para a crise.

\section{a) Impactos da crise}

O Desenho 1 representa a ideia de que a crise tem impactos imediatos e visíveis no bem-estar das populações e nos tipos de cuidados de saúde a que poderão aceder. Acompanha o desenho uma explicação de que a falta de dinheiro não permite cura e de que essa premissa é a representação da crise.

\section{DESENHO 1 - JOSÉ, 12 ANOS. "É MANETA E NÃO TEM DINHEIRO PRA SE CURAR. ISTO É A CRISE"}

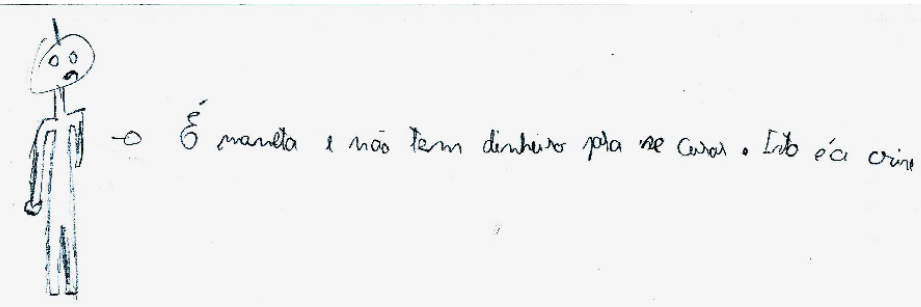

FONTE: acervo do projeto Carta da Cidadania Infanto-Juvenil, Portugal. 
Os contextos familiares são frequentemente os mais vividos e íntimos para as crianças, refletindo diferentes efeitos e constrangimentos para adaptação face a situações de crise económica. Nesse sentido, as crianças encontram nos contextos familiares eventos e acontecimentos que podem ser adaptativos ou disruptivos, quando se instalam, por exemplo, situações de desemprego como aquela que é retratada no Desenho 2.

DESENHO 2 - BEATRIZ, 9 ANOS. "NÃO HÁ TRABALHO"
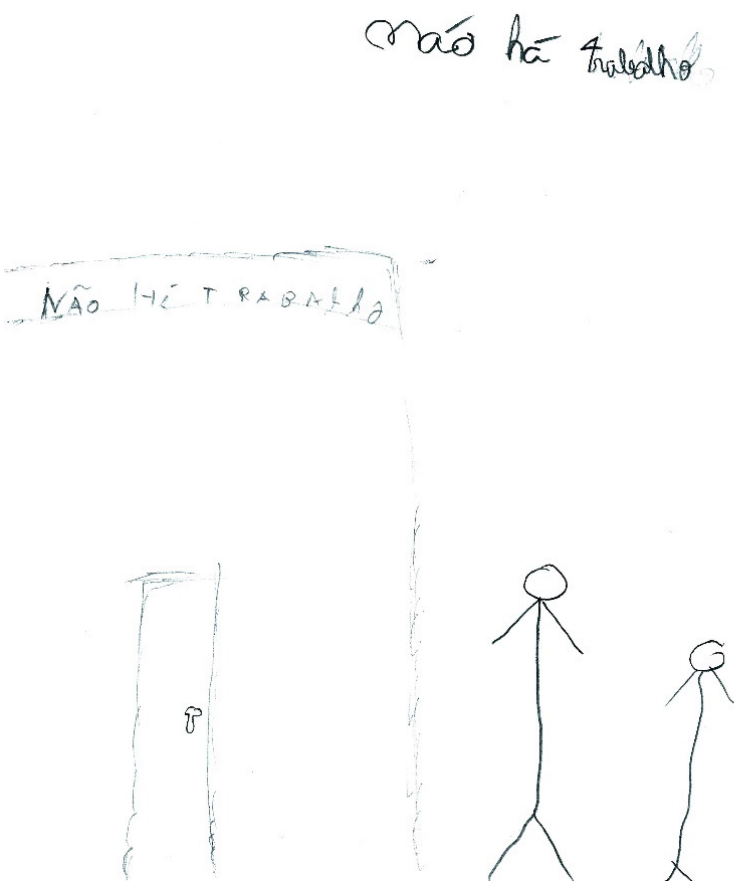

FONTE: acervo do projeto Carta da Cidadania Infanto-Juvenil, Portugal.

\section{b) Pobres e ricos}

As representações gráficas das crianças contemplam, também, a identificação da condição estrutural da pobreza e da sua vivência pelos seus atores, os pobres. As crianças representam graficamente o dinheiro (Desenho 3). O banco, como local de guarda do dinheiro, é representado antes da crise como estando "cheio". No lado direito, o mesmo banco, sem dinheiro e com teias de aranha representando quase um "abandono", refere-se ao banco sem dinheiro. 
DESENHO 3 - SOFIA, 12 ANOS. “ANTES, BANCO COM DINHEIRO. DEPOIS, BANCO SEM DINHEIRO"

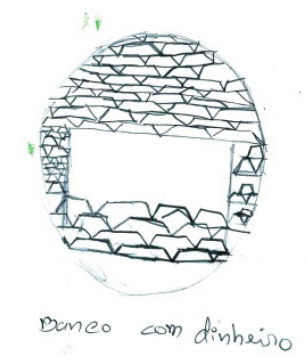

Anters

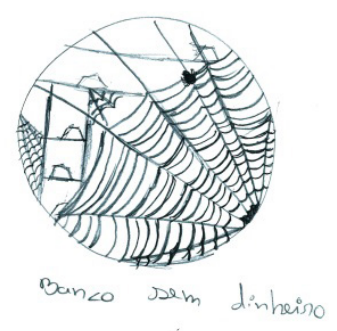

bepois

FONTE: acervo do projeto Carta da Cidadania Infanto-Juvenil, Portugal.

O Desenho 4 respeita já a concretização dessa crise na pessoa, o pobre, representado como não tendo roupa e sendo, por essa mesma razão, pobre. $\mathrm{O}$ pobre é também, segundo esta representação, aquele que não tem os recursos necessários para a compra de bens essenciais e que também por essas razões se torna facilmente identificável enquanto tal.

DESENHO 4 - PAULO, 8 ANOS. "NÃO TEM DINHEIRO. NÃO TEM ROUPA. É POBRE"

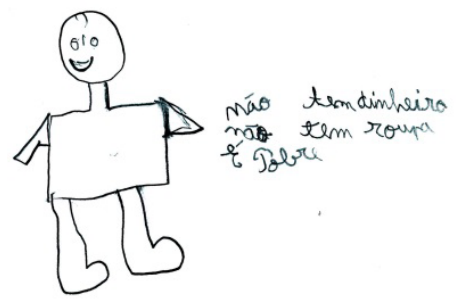

FONTE: acervo do projeto Carta da Cidadania Infanto-Juvenil, Portugal. 
Mas as narrativas gráficas das crianças não colocam apenas a compreensão no fenómeno da pobreza e da sua vivência pelos pobres: para lá disso, são capazes de representar situações de desigualdade social, pela comparação entre os extremos: os ricos e os pobres. Também aqui, o dinheiro surge representado como um dos fatores mais distintivos e marcantes das situações de desigualdade social, sendo a partir dele que essas situações se tornam mais visíveis. Os Desenhos 5 e 6 traçam a representação entre o pobre que não o possui e o rico que tem bastante; entre o rico capaz de aceder a bens essenciais, como roupa, que permitem também aqui traçar elementos de distinção social. A crise é, então, uma questão económica evidente mas também a representação do que a escassez de dinheiro promove ao nível da desigualdade e distinção.

\section{DESENHO 5 - JOÃO, 9 ANOS. "PESSOA RICA. PESSOA POBRE"}

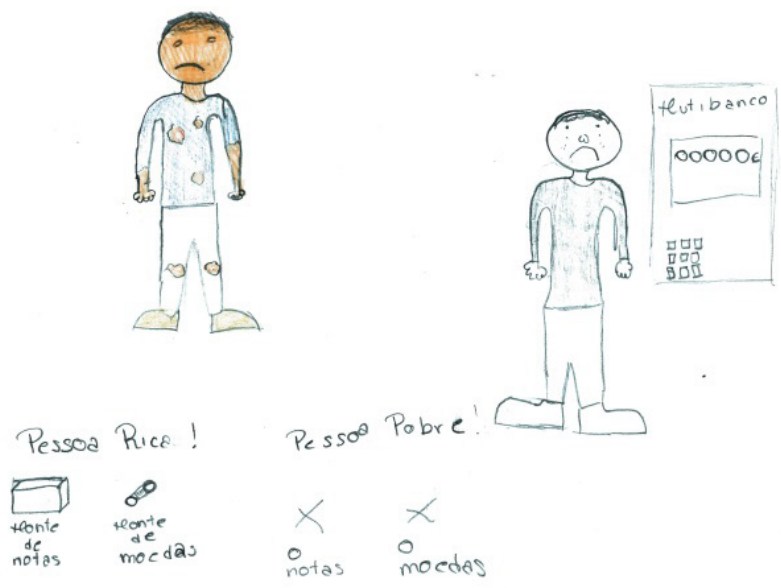

FONTE: acervo do projeto Carta da Cidadania Infanto-Juvenil, Portugal. 
DESENHO 6 - LUISA, 8 ANOS. "CRISE SEM DINHEIRO”

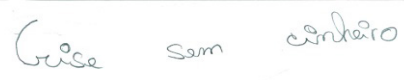

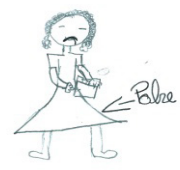

$0 €$

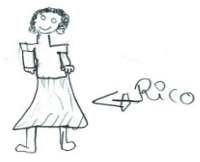

$10000000000 €$

FONTE: acervo do projeto Carta da Cidadania Infanto-Juvenil, Portugal.

\section{c) Representação política}

A par da representação de efeitos diretos e observáveis nas suas vidas e nas dos outros, as crianças, pela exposição diária a partir de diferentes meios, são capazes de identificar diferentes atores dos cenários de decisão política, nomeadamente o primeiro-ministro na altura, Pedro Passos Coelho. Pela função ocupada, aparecerá como o rosto com responsabilidade na situação de crise, pelo que aparece representado no Desenho 7, figurativamente, enquanto forma híbrida - humano e coelho - retirando dinheiro a um adulto.

\section{DESENHO 7 - CONSTANTINO, 10 ANOS. "PASSOS COELHO"}

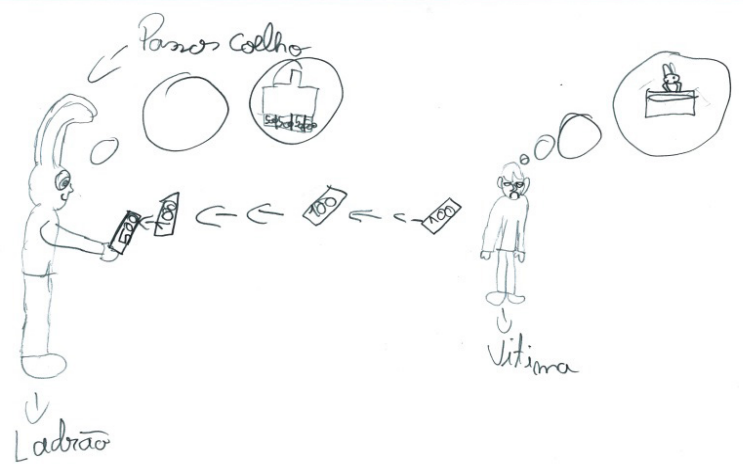

FONTE: acervo do projeto Carta da Cidadania Infanto-Juvenil, Portugal. 


\section{d) Soluções}

Entretanto as crianças não procuram apenas explicar/identificar/enumerar os efeitos e os possíveis responsáveis pelas situações que descrevem. Elas procuram identificar soluções, projetar situações futuras que poderiam ser auxiliares de resolução das situações de adversidade até aí vividas.

Nos Desenhos 8 e 9 aparecem precisamente esse tipo de soluções: o regresso à natureza e à agricultura, simbolizada pela árvore de fruta e o fabrico do próprio pão, que permite despender menos dinheiro e assegurar a alimentação essencial. É no espaço doméstico e pessoal que as "soluções" são procuradas pelas crianças.

\section{DESENHO 8 - INÊS, 9 ANOS}

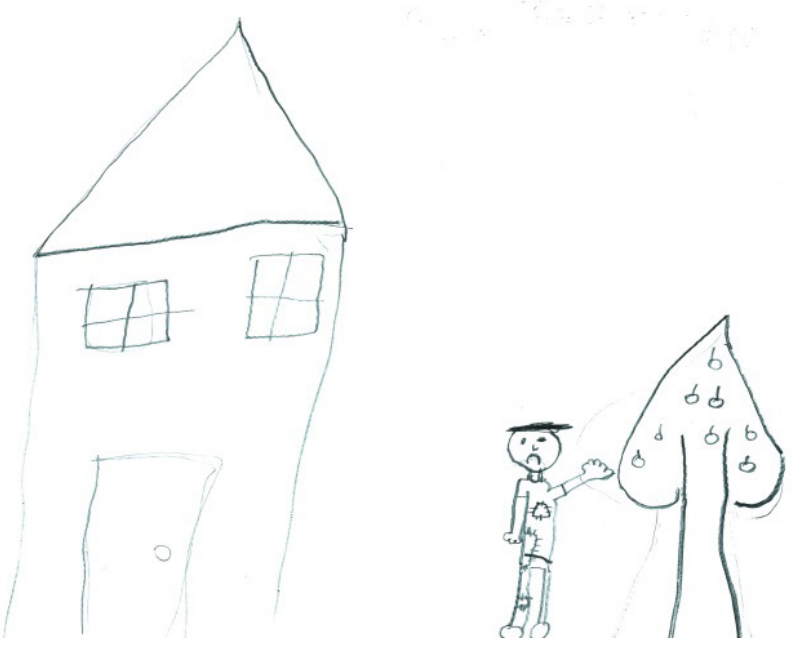

FONTE: acervo do projeto Carta da Cidadania Infanto-Juvenil, Portugal. 
DESENHO 9 - RAFAELA. 11 ANOS. "O FORNO" Crise:

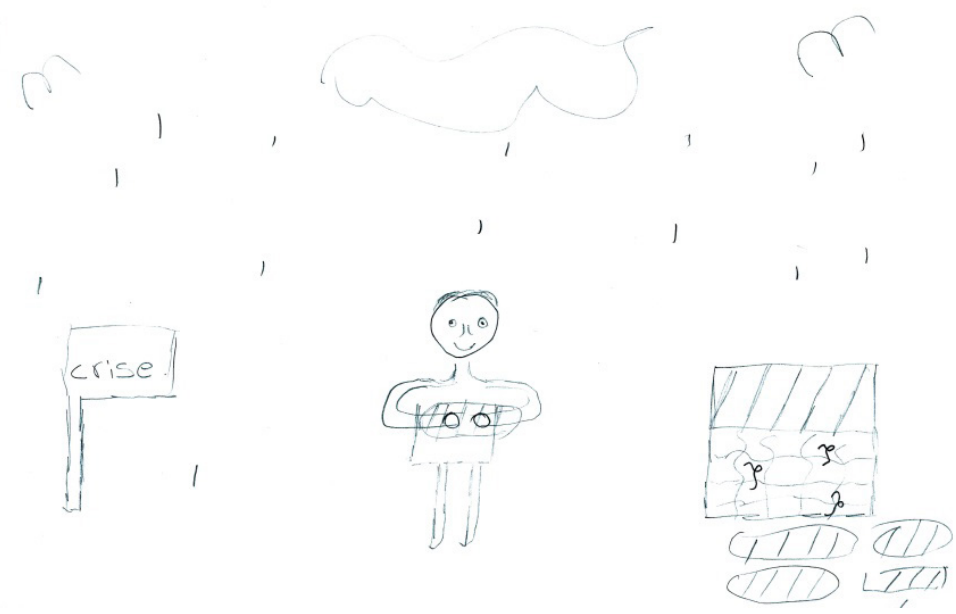

FONTE: acervo do projeto Carta da Cidadania Infanto-Juvenil, Portugal.

\section{Discussão e conclusões}

Os desenhos das crianças procuram ilustrar aquilo que elas pensam sobre uma determinada realidade pessoal, natural ou social. Ao ser-lhes solicitado que desenhassem a crise económica e social, as crianças conceberam formas gráficas de "contar a estória" da crise, fosse ela expressa no aumento da pobreza e no acentuar das desigualdades entre ricos e pobres, fosse ela a dos responsáveis políticos e da sua ação direta, fosse ela ainda a das propostas e soluções de gerir a crise, quase sempre numa perspetiva adaptativa e individual, face aos seus efeitos. Ao fazê-lo, as crianças constroem representações próprias que exprimem as suas representações, mas, mais do que isso, emanam das suas culturas de infância, visto que transfiguram imaginariamente o real para o apresentar nos traços que elas mais salientam e sublinham. Para tanto, as crianças utilizam, para além dos recursos gráficos (no caso desta investigação, eles foram propositadamente pobres nos meios disponibilizados), recursos simbólicos que são estruturantes do conteúdo das mensagens comunicadas, isto é, não são adjacentes mas antes substantivos dos elementos semânticos. 
Desde logo, o humor e a caricatura: a realidade é transfigurada imaginariamente, estabelecendo uma relação de distanciação com os factos e, simultaneamente, subvertendo o poder pela irrisão. No Desenho 7, que produz referência ao ex-primeiro ministro Passos Coelho, é possível observar a especial atenção ao pormenor do coelho no balão de pensamento da vítima: um coelho que saiu da cartola? - uma magia em que o feitiço se virou contra o feiticeiro? Há uma similitude entre a urna e o "chapéu mágico" de onde sai algo: uma pomba, uma flor ou um coelho. Além disso, há uma mesa de poder: o coelho é quem está, literalmente, à mesa do orçamento. $\mathrm{O}$ desenho apresentado não permite fixar-nos em nenhuma interpretação, mas antes permite todas elas. A polissemia é, portanto, um fator acrescido de sentido crítico, fortemente subversivo que é comum à paródia e à caricatura.

A narrativa gráfica segue um processo de metaforização do real. À "secura" das palavras, contrapõe-se a sugestividade da imagem como forma de apreensão sensível de uma realidade que é, ora concetualmente árida (a torneira como símbolo de descapitalização e ausência de liquidez - aliás a própria linguagem económica é feita de catacreses ou metáforas mortas, e.g.:"liquidez"), ora pungente: a teia de aranha, símbolo de paralisia e vazio (Desenho 3). Esta capacidade, de resto, é frequentemente mobilizada pelas crianças quando da produção de diferentes dispositivos que vão para lá da linguagem oral e escrita formalizada.

De certo modo, podemos falar de uma estética expressionista. As crianças procuram uma expressão subjetiva e emocional da crise e fazem-no através da construção por imagens onde a imaginação se propõe, na deformação das visões realistas, dar conta de uma realidade especialmente dramática. O expressionismo compreende a deformação da realidade para expressar de forma subjetiva a natureza e o ser humano, dando primazia à expressão de sentimentos em relação à simples descrição objetiva da realidade: a casa vazia do desemprego tem como consequência a rigidez esquelética dos corpos (Desenho 2); a criança mutilada é o símbolo da doença e da privação da cura (Desenho 1).

No centro, quase sempre, a figura do indivíduo, vítima ou algoz de uma situação socialmente dramática. Na ausência de uma refinada e complexa explicação política e económica da crise, as crianças situam-se a partir do seu campo experiencial e assumem o indivíduo como ponto onde aflui a crise e o seu cortejo de misérias. Uma perspetiva de individualização da figura humana no desenho promove uma visão pessoalizada da crise. Há máquinas, objetos, dinheiro nos desenhos, mas as figuras humanas pessoalizam a representação concreta da riqueza ou da pobreza, da penúria e do sofrimento, até da perversidade e do mal.

Através das suas formas de expressão, nomeadamente das narrativas gráficas que convoca, a criança, individual e coletivamente representada, constrói 
a sua voz sobre as coisas, recorrendo a múltiplos códigos. Isso é inerente à sua condição humana, mas constitui-se como um elemento central das culturas infantis e da sua análise enquanto grupo social e geracional distintivo. A criança confronta-se com a dureza da realidade da crise através de processos interpretativos em que a transfiguração imaginária do real é fundamental para atribuir sentido e para confrontar com as atitudes e comportamentos de ajustamento. A expressão dos modos de interpretação pela mobilização do imaginário é especialmente visível nos desenhos das crianças, pelo que eles constituem um recurso metodológico indispensável para capturar a polivocidade anteriormente referida. Nenhuma interpretação, no entanto, e como foi já referido, se apresenta livre de subjetividades, pelo que se torna importante fazer acompanhar este dispositivo metodológico de outros, nomeadamente a análise discursiva que os acompanha e o modo como ajuda a fornecer interpretações mais rigorosas das intenções das crianças.

A crise económica e social tem importantes consequências na vida das crianças e afeta a infância de forma particular: pobreza infantil, efeitos intrafamiliares, redução de expetativas e aspirações sociais, cortes nas políticas públicas, exposição à violência, redução das oportunidades de participação social. A visão da crise, transfigurada pela imaginação infantil, não apenas propicia "estratégias de lide" às crianças como simultaneamente amplia a possibilidade de entendimento das formas de perceção e das perspetivas e representações coletivas face aos efeitos da crise. A imaginação das crianças apresenta-se, deste modo, como funcional e expressiva, face à realidade social. Mas ela ajuda também a expandir e a amplificar as suas perceções e representações coletivas sobre a crise. Para lá das observações dos efeitos mais negativos, em particular a partir dos seus contextos de vida, como a casa e a escola, as crianças e jovens reclamam o seu "direito ao futuro", isto é, não limitam a sua reflexão ao presente vivido, mas alargam-na a um futuro incerto, onde o seu lugar não é claro.

\section{REFERÊNCIAS}

Bastos, A. (2015). Pobreza infantil. Diagnóstico e reflexão sobre os indicadores de aferição. In F. Diogo, A. Castro e P. Perista (Org.), Pobreza e exclusão social em Portugal. Contextos, transformações e estudos. V.N. de Famalicão: Húmus Editora. pp. 101-113.

Coates, E. \& Coates, A. (2011). The subjects and meanings of young children's drawings, In D. Faulkner, \& E. Coates (Eds.), Exploring Children's Creative Narratives (86-110). London: Routledge. 
De Neubourg, C., Bradshaw, J., Chzhen, Y., Main, G., Martorano, G., \& Menchini, L. (2012). Child Deprivation, Multidimensional Poverty and Monetary Poverty in Europe. Florence: Unicef Innocenti Research Centre (Innocenti Working Paper n. 2012-02).

Eurochild, \& EAPN. (2013) Towards children's well-being in Europe. Explainer on child poverty in the EU. Brussels: Eurochild \& EAPN.

Faulkner, D., \& Coates, E. (2011) (Eds.). Exploring Children's Creative Narratives. London: Routledge

Harper, C., Jones, N., Mckay, A., Espey, J. (2009). Children in times of economic crisis: past lessons, future policies. ODI. 1-12.

Martorano, B., Natali, L., De Neubourg, C., Bradshaw, J. (2013). Child Well-Being in Advanced economies in the late 2000s. Unicef Ofice of research: Florence: Unicef Innocenti Research Centre (Innocenti Working paper 2013-01).

Rodrigues, C. F. (2016) (Coord.). Desigualdade do Rendimento e Pobreza em Portugal: As consequências sociais do programa de ajustamento. Lisboa: Fundação Francisco Manuel dos Santos.

Sarasa, S., Luppi, F. Crisis Economica y pobreza infantil en algunos países de la Unión Europea. (2012). In: NAVARRO, V. (Org.), El Impacto de la Crisis en las Familias y en la Infancia. Barcelona: Ariel, pp. 17-55.

Sarmento, M. J. (2011). Conhecer a infância: os desenhos das crianças como produções simbólicas. In A. J. Martins Filho \& P.D. Prado (Orgs), Das Pesquisas com Crianças à Complexidade da Infância. Campinas: Autores Associados. pp. 27-60 .

Sarmento, M. J. (2014). Metodologias Visuais em Ciências Sociais. In L. L. Torres \& J.A. Palhares (Org), Metodologia de Investigação em Ciências Sociais da Educação. V. N. Famalicão: Húmus; pp. 197-218.

Sarmento, M., Fernandes, N., Trevisan, G. (2015). A redefinição das condições estruturais da infância e a crise económica em Portugal. In F. Diogo, A. Castro, e P. Perista (Orgs.), Pobreza e exclusão social em Portugal. Contextos, transformações e estudos. V.N. de Famalicão: Húmus Editora. pp. 81-99.

Trevisan, G. de P. (2014). Somos as pessoas que temos de escolher, não são as outras pessoas que escolhem por nós. Infância e cenários de participação pública: uma análise sociológica dos modos de codecisão das crianças na escola e na cidade. Tese de Doutoramento em Estudos da Criança. Universidade do Minho.

UNICEF (2012). Measuring child poverty. New tables of child poverty in the world's rich countries. Innocenti Report Card, n. 10. Firenze: Unicef.

Wall, K., Almeida, A. N., Vieira, M. M., Cunha, V., Rodrigues, L., Coelho, F., Leitão, M., Atalaia, S. (2014a). As Crianças e a Crise em Portugal: Vozes de Crianças, Políticas Públicas e Indicadores Sociais, 2013. Lisboa: Unicef. 
Wall, K.; Leitão, M.; Atalaia, S. (2014b). Principais Desenvolvimentos das Políticas de Família em 2013. Lisboa: Observatório das Famílias e das Políticas de Família Instituto de Ciências Sociais da Universidade de Lisboa.

Texto recebido em 24 de março de 2017. Texto aprovado em 27 de abril de 2017. 